\title{
Circulating Th22 cells, as well as Th 17 cells, are elevated in patients with renal cell carcinoma
}

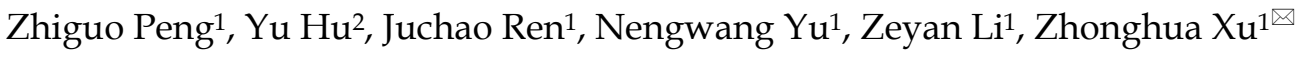 \\ 1. Department of Urology, Qilu Hospital, Shandong University, 107 Wenhua West Road, Jinan 250012, PR China. \\ 2. Department of Medical Oncology, Qilu Hospital, Shandong University, 107 Wenhua West Road, Jinan 250012, PR China. \\ $\triangle$ Corresponding author: Zhonghua Xu, M.D., Ph.D. E-mail: xu_zhonghua@sdu.edu.cn. Department of Urology, Qilu Hospital, Shandong University, 107 \\ Wenhua West Road, Jinan 250012, PR China. Tel: +86 53182166702 \\ (c) The author(s). This is an open access article distributed under the terms of the Creative Commons Attribution License (https://creativecommons.org/licenses/by/4.0/). \\ See http://ivyspring.com/terms for full terms and conditions.
}

Received: 2020.04.24; Accepted: 2020.10.21; Published: 2021.01.01

\begin{abstract}
T-helper (Th) 22 cells serve an essential role in different types of tumors and autoimmune diseases. No research has been conducted to study the role of Th22 cells in the pathogenesis of renal cell carcinoma (RCC). We aimed to evaluate the prognostic value of circulating Th22, Th17, and Th1 cells in RCC patients. Thirty-two newly diagnosed RCC patients and thirty healthy controls were enlisted in the research. Their peripheral blood was collected, and the frequencies of circulating Th22, Th17, and Th1 cells were detected by flow cytometry. Plasma IL-22 concentrations were examined by an enzyme-linked immunosorbent assay (ELISA). Quantitative reverse transcription-polymerase chain reaction (RT-PCR) was used to identify the mRNA expression levels of aromatic hydrocarbon receptor (AHR) and RAR-associated orphan receptor $C$ (RORC) in peripheral blood mononuclear cells (PBMC). Compared with the healthy control group, the frequency of circulating Th22 and Th17 cells and concentrations of plasma IL-22 were significantly increased in RCC patients. However, there was no significant difference in the frequency of Th1 cells. A positive correlation between Th22 cells and plasma IL-22 levels was found in RCC patients. Also, there was a significant positive correlation between Th22 and Th17 cells in RCC patients. An up-regulated expression of AHR and RORC transcription factors were also observed in RCC patients. As tumor stage and grade progressed, the frequencies of Th22 and Th17 cells and the level of plasma IL-22 significantly increased. Meanwhile, there was a positive correlation between Th22 and Th17 cells and RCC tumor stage or grade. Furthermore, patients with high Th22 or Th17 cells frequency displayed a decreased trend in survival rate. Our research indicated that the increased circulating Th22 and Th17 cells and plasma IL-22 may be involved in the pathogenesis of RCC and may be involved in the occurrence and development of tumors. Th22 cells, plasma IL-22, and Th17 cells may be promising new clinical biomarkers and may be used as cellular targets for RCC therapeutic intervention.
\end{abstract}

Key words: renal cell carcinoma; Th22 cells; Th17 cells; interleukin-22

\section{Introduction}

Renal cell carcinoma (RCC) represents $2-3 \%$ of all cancers worldwide and has a worldwide estimated incidence of approximately 300,000 cases and mortality of 129,000 deaths every year [1-3]. Different factors, such as cigarette smoking, obesity, asbestos exposure, and regular use of analgesics, are thought to promote RCC development, but its etiology is still unknown [4-6]. Although surgical nephrectomy is effective in treating RCC patients who have no evidence of metastases, controlling RCC that is at an advanced-stage remains a challenge due to the lack of reliable biomarkers [7, 8]. Therefore, identifying reliable markers for early detection or use as a prognostic factor is essential.

Studies have shown that cellular immunity plays a vital role in the pathogenesis of $\operatorname{RCC}[9,10]$. The $\mathrm{CD}^{+} \mathrm{T}$ cell subset reflects the immune function state and is critical in the maintenance of homeostasis and tumorigenesis [11]. CD4 ${ }^{+} \mathrm{T}$ cells can differentiate into many active subsets, including T-helper (Th) 1, Th2, Th17, and Treg cells. Previous evidence has suggested that these Th subsets are associated with the 
pathogenesis and progression of some solid tumors [12-15]. Th22 cells are a newly identified subset of $\mathrm{CD}^{+} \mathrm{T}$ cell that is characterized by the secretion of IL-22, but not IFN- $\gamma$ or IL-17 [16, 17]. Th22 cells are similar to Th17 cells in the expression of chemokine (C-C motif) receptor 6 (CCR6) and CCR4. Compared with Th17 cells, Th22 cells express CCR10 but do not express CD161 [18]. Furthermore, Th22 cells differ from Th17 and Th1 cells in that they have low level expression of the Th1 and Th17 transcription factors T-bet and RORC, while AHR is considered to be the main transcription factor of the Th22 subset [19]. Additionally, under conditions of coexisting IL-6 and tumor necrosis factor- $\alpha$ (TNF- $\alpha$ ), naive $\mathrm{CD}^{+}$cells can differentiate into Th22 subtypes [17]. Based on the above, Th22 cells represent a particular and terminally-differentiated Th subset [16].

The main effector cytokine of Th22 cells is IL-22. IL-22 exerts its biological effects by a heterodimeric transmembrane receptor complex composed of IL-22R1 and IL-10R2, as well as subsequent Janus kinase-signal transducers and activators of transcription (JAK-STAT) signaling pathways, consisting of STAT-3, Jak1, and Tyk2 [20]. Recent studies showed that Th22 cells and IL-22 might participate in the pathogenesis of some tumors, such as multiple myeloma [21], gastric cancer [22], hepatocellular carcinoma [23], and colorectal cancer [24]. These studies suggest a possible role of Th22 cells in tumorigenesis, and it may represent a new type of tumor biomarker. As we all know, no data are available on the role of Th22 cells or IL-22 in the pathogenesis of RCC. Our study investigated the prevalence of Th22, Th17, and Th1 cells in peripheral blood of patients with RCC. The relevant quantitative mRNA expressions of transcription factors such as $\mathrm{AHR}$ and RORC were also investigated. Furthermore, we evaluated the associations of Th22 cells and IL-22 with different tumor stages or grades of RCC to identify their potential predictive and prognostic importance.

\section{Materials and methods}

\section{Patients and controls}

Thirty-two newly diagnosed RCC patients (20 males and 12 females; age range, 31-63 years; median age, 52 years) who had been scheduled for surgery in Qilu Hospital between June 2016 and October 2018 were enrolled in our research. RCC patients with other cancers or autoimmune diseases, including Crohn's disease, psoriasis, systemic lupus erythematosus (SLE), and rheumatoid arthritis (RA) were not included in our research. No patient had received anticancer therapy before the operation.
Physical examination and computed tomography (CT)/ magnetic resonance imaging (MRI) was used for clinical staging. Tumors were classified and staged according to the American Joint Committee on Cancer's tumor-node-metastasis (TNM) classification system (Edition 8). Stages I-II and III-IV were regarded as early and advanced stages of the disease, respectively. The tumor grade was assigned according to the WHO/ISUP grading system. The critical clinical information of the RCC patients is given in Table 1 . Thirty healthy controls (17 males and 13 females; age range, 23-49 years; median age, 28 years) were also enrolled in our research. This study was approved by the Medical Ethical Committee of Qilu Hospital of Shandong University. According to the Declaration of Helsinki, informed consent was obtained from all patients before participating in this research.

Table 1. Clinical characteristics of the Study Subjects

\begin{tabular}{lll}
\hline Variable & RCC patients $(\mathrm{n}=32)$ & healthy controls $(\mathrm{n}=30)$ \\
\hline age (median, range), y & $52(31-63)$ & $28(23-49)$ \\
Gender (male/female), n & $20 / 12$ & $17 / 13$ \\
TNM stage (I+II/III+IV), n & $17 / 15$ & - \\
WHO/ISUP grade & $22 / 10$ & - \\
(I+II/III+IV), n & & - \\
Pathology & & - \\
Clear cell & 29 & - \\
Papillary & 3 & \\
\hline
\end{tabular}

\section{Flow cytometric analysis of Th22, Th17, and ThI cells}

Measurements of intracellular cytokines by flow cytometry were used to reflect cytokine-producing cells. In short, heparinized peripheral whole blood $(400 \mu \mathrm{L})$ was incubated with an equal volume of Roswell park memorial Institute (RPMI)-1640 medium for $4 \mathrm{~h}$ at $37^{\circ} \mathrm{C}$ in $5 \% \mathrm{CO}_{2}$ under coexisting condition of $25 \mathrm{ng} / \mathrm{mL}$ of phorbol myristate acetate (PMA), $1.7 \mathrm{mg} / \mathrm{mL}$ of monensin, and $1 \mathrm{mg} / \mathrm{mL}$ of ionomycin (all from Alexis Biochemicals, San Diego, CA, USA).

Monensin was used to inhibit intracellular transport mechanisms and caused cytokines to accumulate in the cells. PMA and ionomycin are pharmacological $\mathrm{T}$ cell activators that mimic the signals produced by the $\mathrm{T}$ cell receptor (TCR) complex, with the advantage of stimulating any antigen-specific T cells. When PMA activates cells, $\mathrm{CD}^{+}$has a tendency to be down modulated. For this reason, to define $\mathrm{CD}^{+} \mathrm{T}$ cells, we stained the cells with APC-Cy7-conjugated anti-CD3 and PE-Cy7conjugated anti-CD8 monoclonal antibodies. After incubation for 20minutes at room temperature in the dark with the monoclonal antibodies, the cells were fixed, permeabilized, and stained with PE-conjugated 
anti-IL-17 monoclonal antibodies, FITC-conjugated anti-IFN- $\gamma$ monoclonal antibodies, and APC-conjugated anti-IL-22 monoclonal antibodies. All antibodies were from eBioscience (San Diego, CA, USA). Isotype controls were used to ensure correct compensation and to confirm the specificity of the antibody. Stained cells were analyzed by flow cytometry using a FACS Calibur cytometer equipped with CellQuest software (BD Bioscience PharMingen, San Jose, CA, USA).

Th22, Th17, and Th1 cells were defined as $\mathrm{CD}^{+}{ }^{+} \mathrm{CD} 8-\mathrm{IFN}-\gamma^{-} \mathrm{IL}-17-\mathrm{IL}-22^{+}, \quad \mathrm{CD} 3{ }^{+} \mathrm{CD} 8-\mathrm{IFN}-\gamma^{-} \mathrm{IL}-$ $17^{+} \mathrm{IL}^{-22^{-}}$cells and $\mathrm{CD} 3^{+} \mathrm{CD} 8-\mathrm{IFN}-\gamma^{+}$, respectively.

\section{Quantitative real-time PCR analysis of transcription factors}

Total RNA was isolated by TRIzol (Invitrogen, USA) according to the manufacturer's instructions. The Prime Script RT reagent kit (Perfect Real Time; Takara) was used for reverse transcription reactions in line with the manufacturer's instructions. Reverse transcription reaction was performed at $37^{\circ} \mathrm{C}$ for 15 minutes and then at $85^{\circ} \mathrm{C}$ for 5 seconds. Real-Time quantitative PCR was done in Roche Applied Science Light Cycler ${ }^{\circledR} 480$ II Real-time PCR systems (Roche Applied Science) conforming to the manufacturer's recommendations. The Real-time PCR reaction included, in a final volume of $20 \mu \mathrm{L}, 1 \mu \mathrm{L}$ of cDNA, $10 \mu$ Lof $2 \times$ SYBR Green Real-Time PCR Master Mix, and $1 \mu \mathrm{L}$ each of the forward and reverse primers. The primers of RORC, AHR, and the endogenous control $\beta$-actin were as follows: RORC: forward 5'-TTT TCC GAG GAT GAG ATTGC- $3^{\prime}$ and reverse, 5'-CTT TCC ACA TGC TGG CTACA-3'; AHR: forward 5'-CAA ATC CTT CCA AGC GGC ATA-3' and reverse, 5'-CGC TGA GCC TAA GAA CTG AAA G-3'; $\beta$-actin: forward 5'-CCT TCC TGG GCA TGG AGT CCT G-3' and reverse, 5'-GGA GCA ATG ATC TTG ATC TTC-3'. PCR products were analyzed by melting curve analysis and agarose gel electrophoresis to confirm product size and ensure that no by-products were formed. The results of the targets were expressed relative to $\beta$-actin transcripts as the internal control. All experiments were repeated three times.

\section{IL-22 enzyme-linked immunosorbent assay}

Peripheral blood samples were taken from a forearm vein into heparin-anticoagulant vacutainer tubes. Plasma was obtained from all subjects by centrifugation and stored at $-80^{\circ} \mathrm{C}$ for determining the concentration of cytokine IL-22. Plasma IL-22 concentration was determined using the quantitative sandwich enzyme immunoassay technique in line with the manufacturer's instructions.

\section{Statistical analysis}

The results are expressed as the median (range) or mean \pm SEM (standard error of the mean). Comparisons between the two groups were analyzed by the Wilcoxon rank-sum test. In correlation analyses, the Spearman's correlation test was used for the non-normal distribution data, and the Pearson's correlation test was used for the normal distribution data. Patient overall survival was defined as the time interval between the date of surgery and the date of death or last follow-up. Deaths due to causes other than RCC were not included in the death record. The cumulative survival time was analyzed with the use of Kaplan-Meier method, and the log-rank test was used to compare group differences. All statistical tests were performed using GraphPad Prism 6.0 software (GraphPad, San Diego, CA, United States) and SPSS (version 17.0; SPSS, Inc., Chicago, IL, USA). $P<0.05$ was considered statistically significant.

\section{Results}

\section{Increased percentage of circulating Th22 cells and plasma IL-22 levels in RCC patients}

Using multicolor flow cytometry, we examined the percentage of Th22 cells from the cytokine patterns after in vitro activation by PMA/ionomycin in short-term cultures. After gating on $\mathrm{CD}^{+} \mathrm{CD}^{-}$ cells, we identified Th22 (CD3 ${ }^{+} \mathrm{CD} 8^{-} \mathrm{IFN}-\gamma^{-} \mathrm{IL}^{-}$ 17-IL-22+), Th17 $\left(\mathrm{CD}^{+}{ }^{+} \mathrm{CD} 8-\mathrm{IFN}-\gamma^{-} \mathrm{IL}^{-17}{ }^{+} \mathrm{IL}^{-22}{ }^{-}\right)$, and Th1 $\left(\mathrm{CD}^{+}{ }^{+} \mathrm{CD} 8-\mathrm{IFN}-\gamma^{+}\right)$cells. A representative dot plot of circulating Th22, Th17, and Th1 cells in typical RCC patients and healthy controls are presented in Fig. 1. Compared with the healthy controls, the percentage of circulating Th22 cells in total peripheral $\mathrm{CD}^{+}{ }^{+} \mathrm{CD} 8-$ lymphocytes of RCC patients was significantly increased $(1.97 \pm 0.32 \%$ vs. $0.75 \pm 0.05 \%$, ${ }^{* *} P<0.001$; Fig. 2A). A significant increase in the plasma IL-22 levels of RCC patients compared with healthy controls was also observed $(27.38 \pm 0.75$ pg/mL vs. $20.06 \pm 0.54 \mathrm{pg} / \mathrm{mL}^{* * *} P<0.001$; Fig. $2 \mathrm{~B}$ ). Furthermore, a positive correlation between the percentage of Th22 cells and plasma IL-22 concentration was found in the RCC patients $\left(\mathrm{r}=0.4277,{ }^{*} P<0.05\right.$; Fig. $\left.2 \mathrm{C}\right)$ while no correlation was found in the healthy controls $(r=-0.1361, P=0.4734$; Fig. 2D).

\section{Increased percentage of circulating Th 17 cells in $R C C$ patients}

The percentage of Th17 cells in the RCC patients was significantly higher than the healthy controls $\left(3.18 \pm 0.40 \%\right.$ vs. $1.27 \pm 0.13 \%,{ }^{* * *} P<0.001$; Fig. $\left.3 \mathrm{~A}\right)$. Meanwhile, we found a positive correlation between Th22 and Th17 cells in RCC patients $(r=0.4816$, 
${ }^{* *} P<0.01$; Fig. $3 \mathrm{~B}$ ). Nevertheless, there was no significant correlation between Th22 cells and Th17 cells in the healthy controls ( $\mathrm{r}=-0.1311, P=0.4900$; Fig. $3 C)$.

\section{Association between Th22 cells and Th1 subsets in RCC patients}

There was no significant difference in the percentage of circulating Th1 cells between RCC patients and healthy controls $(18.08 \pm 1.18 \%$ vs. $15.65 \pm$ $1.27 \%, P=0.1676$; Fig. 3D). Furthermore, no significant correlation was found between Th1 and Th22 cells in RCC patients $(r=0.1644, P=0.3686$; Fig. 3E) or healthy controls $(r=0.0247, P=0.8967$; Fig. $3 F)$.

\section{Elevated AHR and RORC mRNA in RCC patients}

We tested the related transcriptional factors of Th22 and Th17 cells by RT-PCR. The results showed that there was a higher level of AHR mRNA in the RCC patients than the healthy controls $(0.47 \pm 0.07 \%$ vs. $0.23 \pm 0.05 \%,{ }^{*} P<0.05$; Fig. $\left.4 \mathrm{~A}\right)$. Furthermore, the RORC mRNA level in the RCC patients was also higher than in the healthy controls $(0.38 \pm 0.06 \%$ vs. $0.18 \pm 0.03 \%,{ }^{*} P<0.05$; Fig. $\left.4 \mathrm{~B}\right)$. The results obtained confirmed the flow cytometry and ELISA data.

\section{Elevated proportions of Th22 and Th17 cells in different tumor stages}

RCC patients with stage III-IV had a significantly higher percentage of circulating Th22 cells than patients with stage I-II $(2.70 \pm 0.61 \%$ vs. 1.34 $\pm 0.22 \%,{ }^{*} P<0.05$; Fig. $\left.5 \mathrm{~A}\right)$. Furthermore, the IL-22 concentration in stage III-IV patients was significantly elevated compared to patients in stage I-II (30.02 \pm $0.94 \mathrm{pg} / \mathrm{ml}$ vs. $25.06 \pm 0.81,{ }^{*} P<0.01$; Fig. $\left.5 \mathrm{D}\right)$. RCC patients with stage III-IV also had a significantly higher percentage of circulating Th17 cells than patients with stage I-II $(4.07 \pm 0.68 \%$ vs. $2.40 \pm 0.40 \%$, ${ }^{*} P<0.05$; Fig. 5B). No significant difference was found between the percentage of Th1 cells and tumor stage $(18.95 \pm 1.65 \%$ vs. $17.31 \pm 1.71 \%, P=0.4933$; Fig. 5 C) .

\section{Elevated proportions of Th22 and Th 17 cells with different grades of RCC}

RCC patients with grade III-IV had a significantly higher percentage of circulating Th22 cells than patients with grade I-II $(3.17 \pm 0.84 \%$ vs. $1.42 \pm 0.20 \%,{ }^{*} P<0.05$; Fig. $\left.6 \mathrm{~A}\right)$. The IL-22 concentration in grade III-IV patients was significantly elevated compared to patients with grade I-II $(29.90 \pm 1.17 \mathrm{pg} / \mathrm{mL}$ vs.26.24 \pm 0.86 , ${ }^{*} P<0.05$; Fig. 6D). RCC patients with grade III-IV also had a significantly higher percentage of circulating Th17 cells than patients with grade I-II $(4.66 \pm 0.90 \%$ vs. $2.51 \pm 0.36 \%,{ }^{*} P<0.05$; Fig. $\left.6 \mathrm{~B}\right)$. Nevertheless, there was no significant difference between the percentage of Th1 cells and tumor grade $(18.98 \pm 2.16 \%$ vs. $17.62 \pm$ $1.43 \%, P=0.6004$; Fig. 6C).
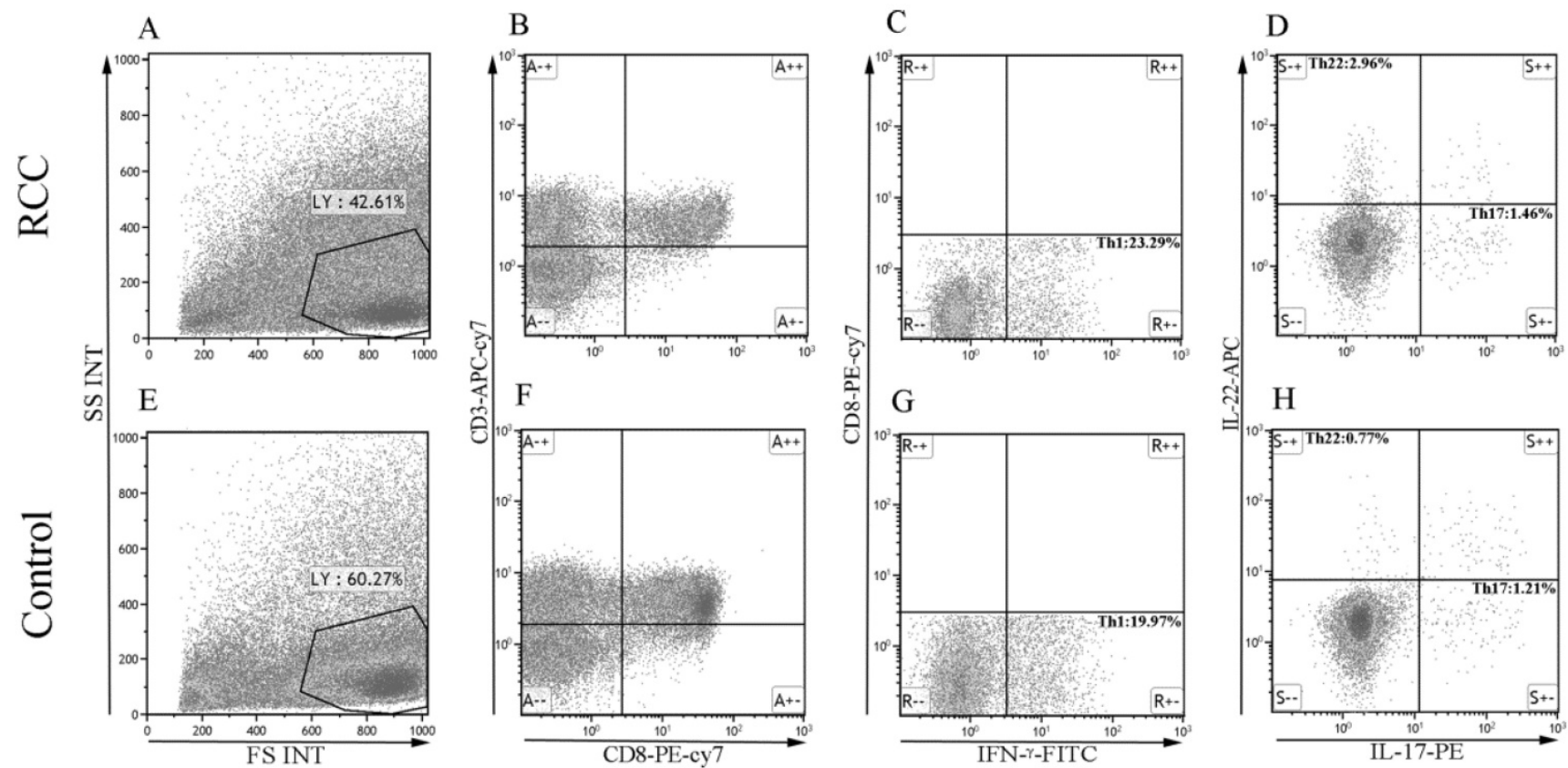

Figure 1. The percentage of Th22, Th17, and Th1 cells in representative RCC patients and healthy controls. (A, E) Circulating lymphocytes were gated by flow cytometry. (B, F) The percentage of circulating $C D 3^{+} C D 8^{-}$lymphocytes was gated by flow cytometry. (C, G) The percentage of circulating $C D 3^{+} C D 8^{-}$IFN- $\gamma^{-}$or $C D 3^{+} C D 8^{-}$IFN- $\gamma^{+}{ }^{-}$cells was

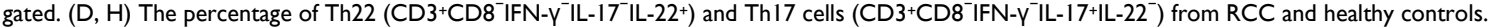




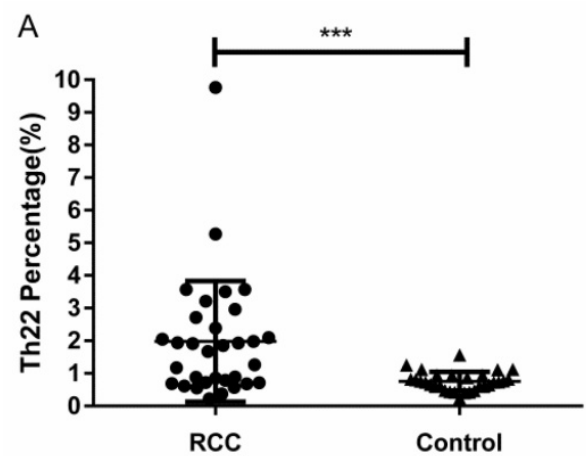

RCC

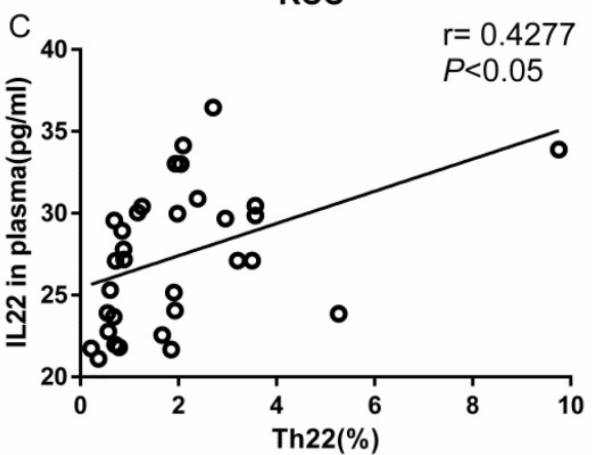

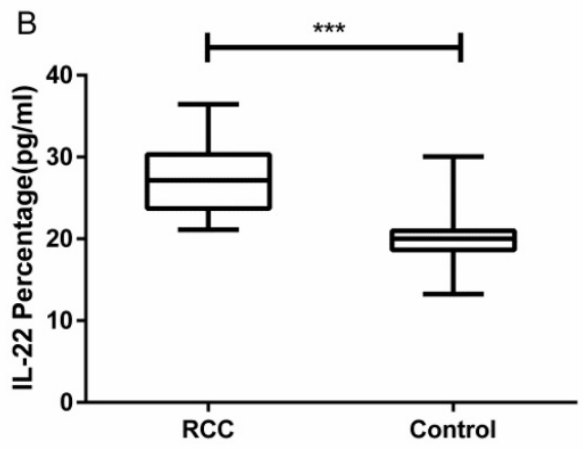

Control

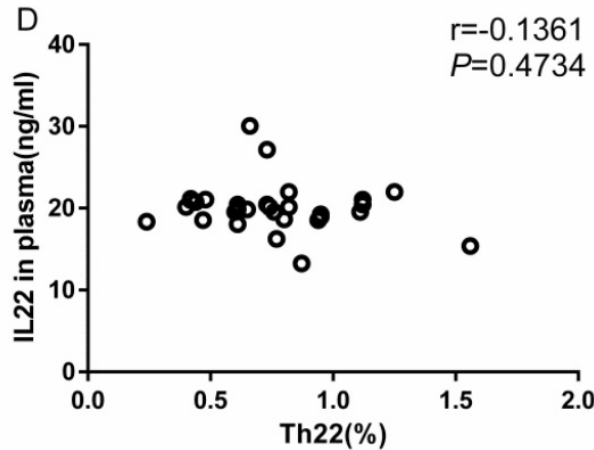

Figure 2. Th22 cells population and concentration of IL-22 in plasma from RCC patients and healthy controls. (A) Significantly elevated percentage of Th22 cells was found in RCC patients compared with healthy controls $(1.97 \pm 0.32 \%$ vs. $0.75 \pm 0.05 \%$, ***P<0.001). (B) IL-22 concentration was significantly increased in RCC patients compared with healthy controls $(27.38 \pm 0.75 \mathrm{pg} / \mathrm{ml}$ vs. $20.06 \pm 0.54 \mathrm{pg} / \mathrm{ml} * * * P<0.001)$. (C) A positive correlation between Th22 cells and IL-22 was found in RCC patients $(r=0.4277, * P<0.05)$. (D) The correlation was not found in healthy controls $(r=-0.1361, P=0.4734)$.
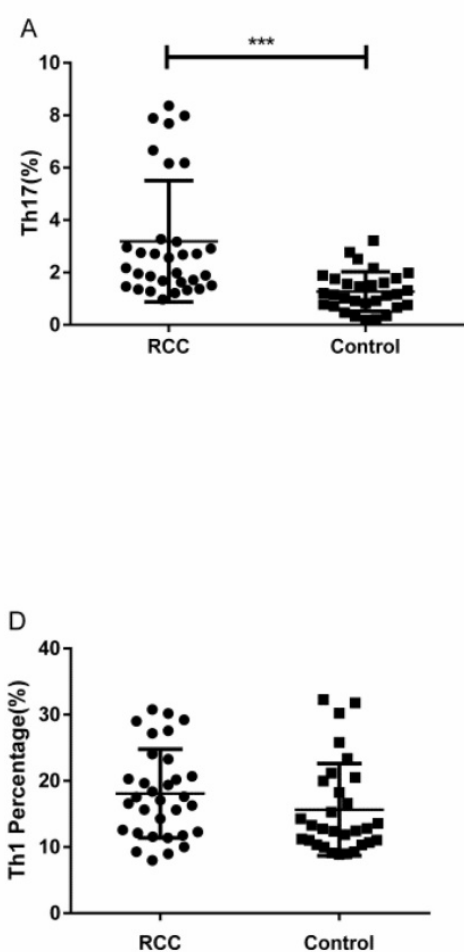
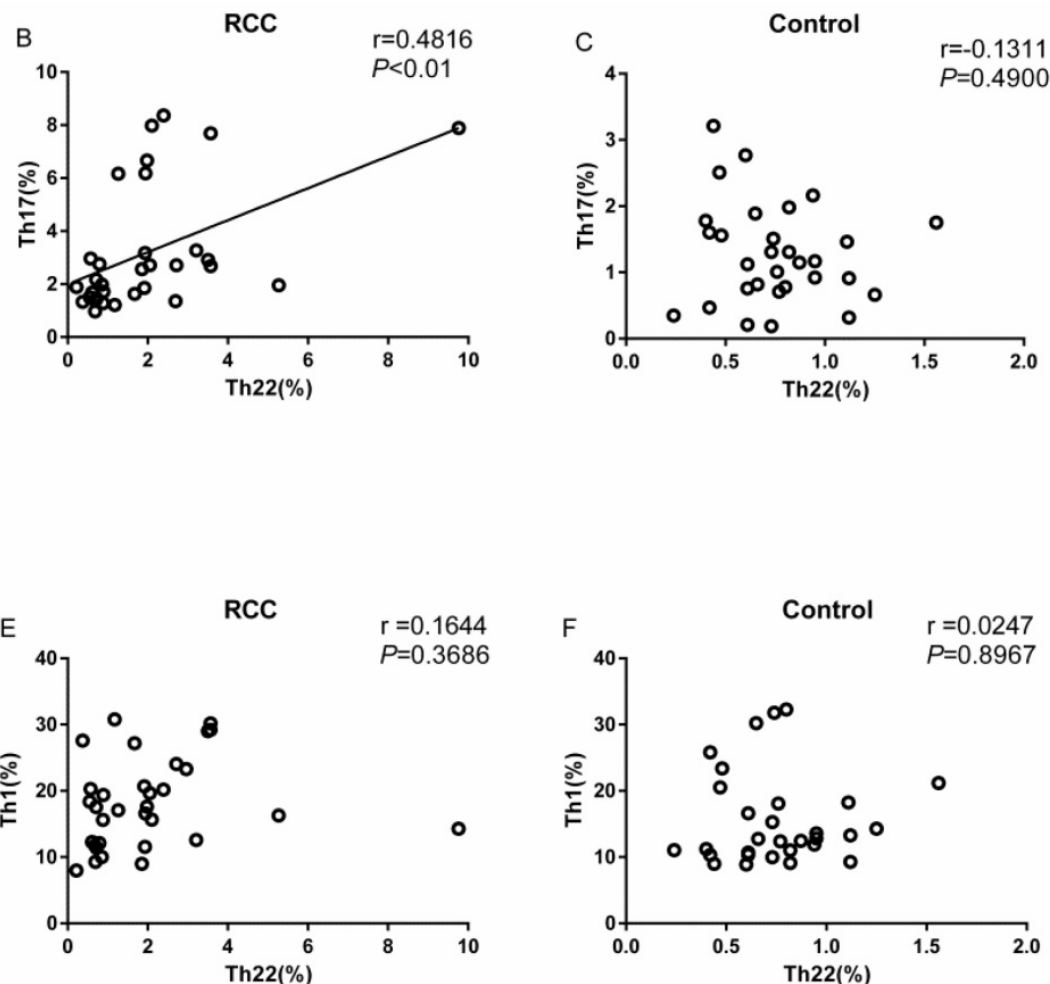

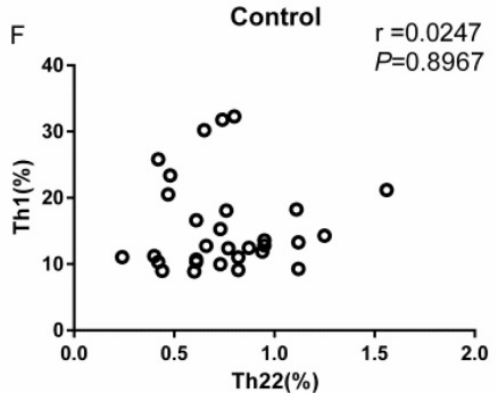

Figure 3. The percentage of Th17 cells with correlations between Th22 and Th17 or Th1 cells in RCC and healthy controls. (A) There was a significantly increased percentage of Th17 cells in RCC patients compared with healthy controls $(3.18 \pm 0.40 \%$ vs. $1.27 \pm 0.13 \%, * * * P<0.001)$. (B) A positive correlation between the percentage of Th22 and Th17 cells was found in RCC patients $(r=0.4816$, $* * P<0.01)$. (C) There was no correlation in the healthy controls $(r=-0.1311, P=0.4900)$. (D) No significant difference was found in the percentage of circulating Thl cells between RCC patients and healthy controls ( $18.08 \pm 1.18 \%$ vs. $15.65 \pm 1.27 \%, P=0.1676)$. (E, $F)$ No significant correlation was found between Th22 and Th1 cells in RCC patients $(r=0.1644, P=0.3686)$ or healthy controls $(r=0.0247, P=0.8967)$. 

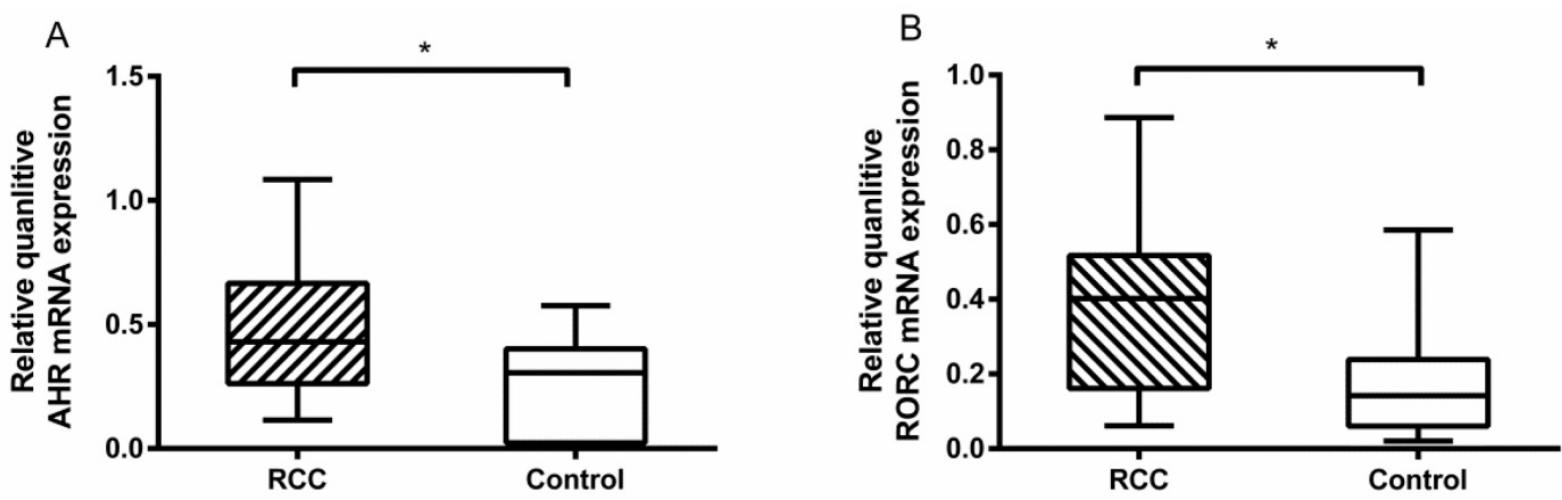

Figure 4. Quantitative RT-PCR for AHR and RORC expressions in RCC patients and healthy controls. (A) There was a higher measured value of $A H R$ mRNA in RCC patients than healthy controls $(0.47 \pm 0.07 \%$ vs. $0.23 \pm 0.05 \%, * P<0.05$. $)(B)$ There was a higher measured value of RORC mRNA in RCC patients than healthy controls $(0.38 \pm 0.06 \%$ vs. $0.18 \pm 0.03 \%, * P<0.05)$.
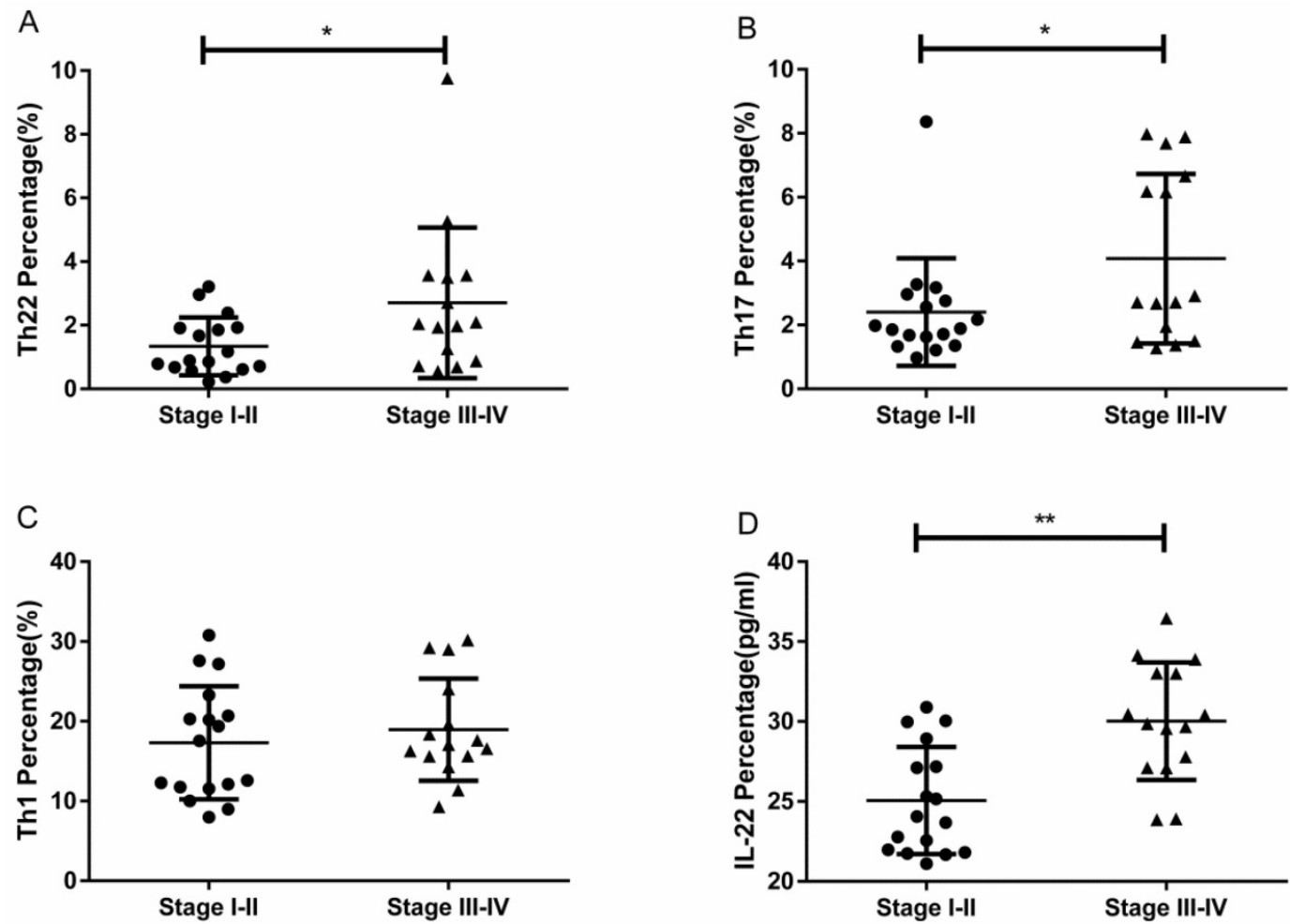

Figure 5. The percentage of circulating Th22, Th17, and Th1 cells and plasma IL-22 concentration in RCC patients with stage III-IV and stage I-II. (A) There was a significantly higher percentage of circulating Th22 cells in stage III-IV RCC patients than stage I-II patients $(2.70 \pm 0.61 \%$ vs. $1.34 \pm 0.22 \%$, $* P<0.05)$. (B) There was also a significantly higher percentage of circulating Th17 cells in stage III-IV RCC patients than stage I-II patients $(4.07 \pm 0.68 \%$ vs. $2.40 \pm 0.40 \%$, $* P<0.05)$. (C) There was no significant difference between the Th1 cell percentage and tumor stage in RCC patients ( $18.95 \pm 1.65 \%$ vs. $17.31 \pm 1.71 \%, P=0.4933)$. (D) There was a significantly higher concentration of IL-22 in stage III-IV

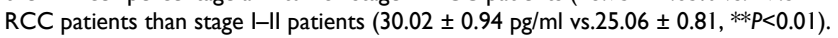

The overall correlation of Th22, Th17 and Th1 cells with tumor stage and grade in RCC patients.

A positive correlation was found between Th22 cells and tumor stage or grade in RCC patients $\left(\mathrm{r}=0.6114,{ }^{* *} P<0.01\right.$; Fig. $7 \mathrm{~A}$; $\mathrm{r}=0.3865,{ }^{*} P<0.05$; Fig. 7D). Meanwhile, there was also a positive correlation between Th17 cells and tumor stage or grade in RCC patients $\left(\mathrm{r}=0.4861,{ }^{*} \mathrm{P}<0.01\right.$; Fig. $7 \mathrm{~B} ; \mathrm{r}=0.4646$, ${ }^{* *} P<0.01$; Fig. 7E). Nevertheless, there was no significant correlation between Th1 cells and tumor stage or grade in RCC patients $(r=0.3003, P=0.0949$;
Fig. 7C; $r=0.1265, P=0.4904$; Fig. 7F).

The prognostic value of circulating Th22, Th17 and Th 1 cells for the overall survival of RCC patients.

We evaluated the prognostic value of high and low levels of circulating Th22, Th17 and Th1 cells on the overall survival of RCC patients. There was a tendency for a decreased trend in the 24-month survival rate in the high percentage Th22 cell group compared to low percentage Th22 cell group, although this difference was not statistically significant (Fig. 8A). A similar survival rate trend was 
obtained when comparing patients with high versus low Th17 cell percentages (Fig. 8B). However, no similar trend of survival rate was found in patients
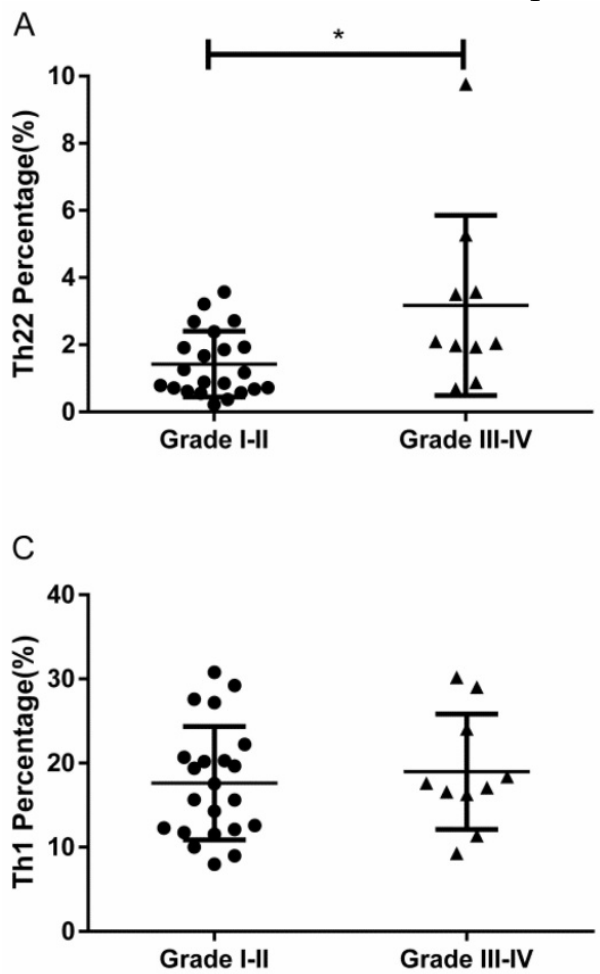

between high versus low Th1 cell percentage level (Fig. 8C).
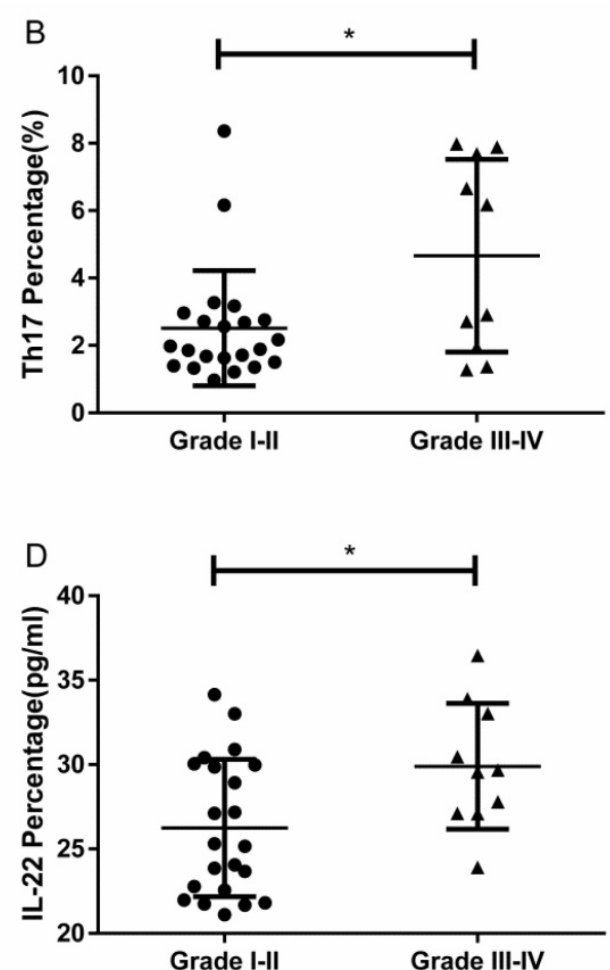

Figure 6. The percentage of circulating Th22, Th17, and Th1 cells and plasma IL-22 concentration in patients with different grades of RCC. (A) There was a significantly higher percentage of circulating Th22 cells in grade III-IV RCC patients than grade I-II patients $(3.17 \pm 0.84 \%$ vs. $1.42 \pm 0.20 \%$, $* P<0.05)$. (B) There was also a significantly higher percentage of circulating Th17 cells in grade III-IV RCC patients than grade I-II patients $(4.66 \pm 0.90 \%$ vs. $2.51 \pm 0.36 \%$, $* P<0.05)$. (C)There was no significant difference between the percentage of Thl cells and tumor grade in RCC patients $(18.98 \pm 2.16 \%$ vs. $17.62 \pm 1.43 \%, P=0.6004)$. (D) There was a significantly higher concentration of IL-22 in grade III-IV RCC patients than grade I-II patients $(29.90 \pm 1.17 \mathrm{pg} / \mathrm{ml}$ vs.26.24 $\pm 0.86, * P<0.05)$.
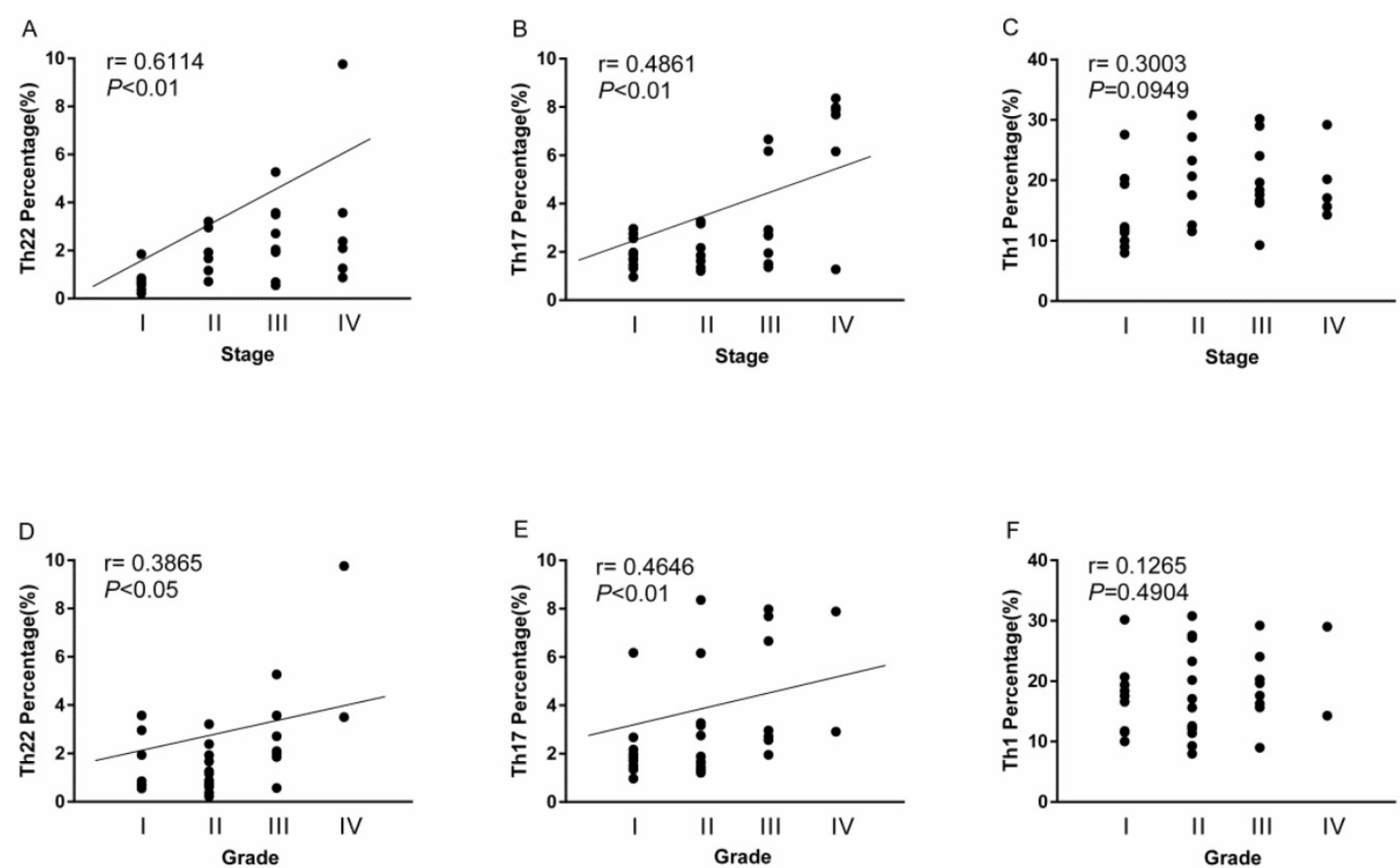

Figure 7. Association of circulating Th22, Th17, and Th1 cells with tumor stage and grade. (A, D) A positive correlation was found between Th22 cells and tumor stage $(r=0.6114, * * P<0.01)$ or grade $(r=0.3865, * P<0.05)$ in RCC patients; $(B, E) A$ positive correlation was also found between Th17 cells and tumor stage $(r=0.4861, * * P<0.01)$ or grade $(r=0.4646, * * P<0.01)$ in RCC patients; $(C, F)$ There was no significant correlation between Thl cells and tumor stage $(r=0.3003, P=0.0949)$ or grade $(r=0.1265, P=0.4904)$ in RCC patients. 
A
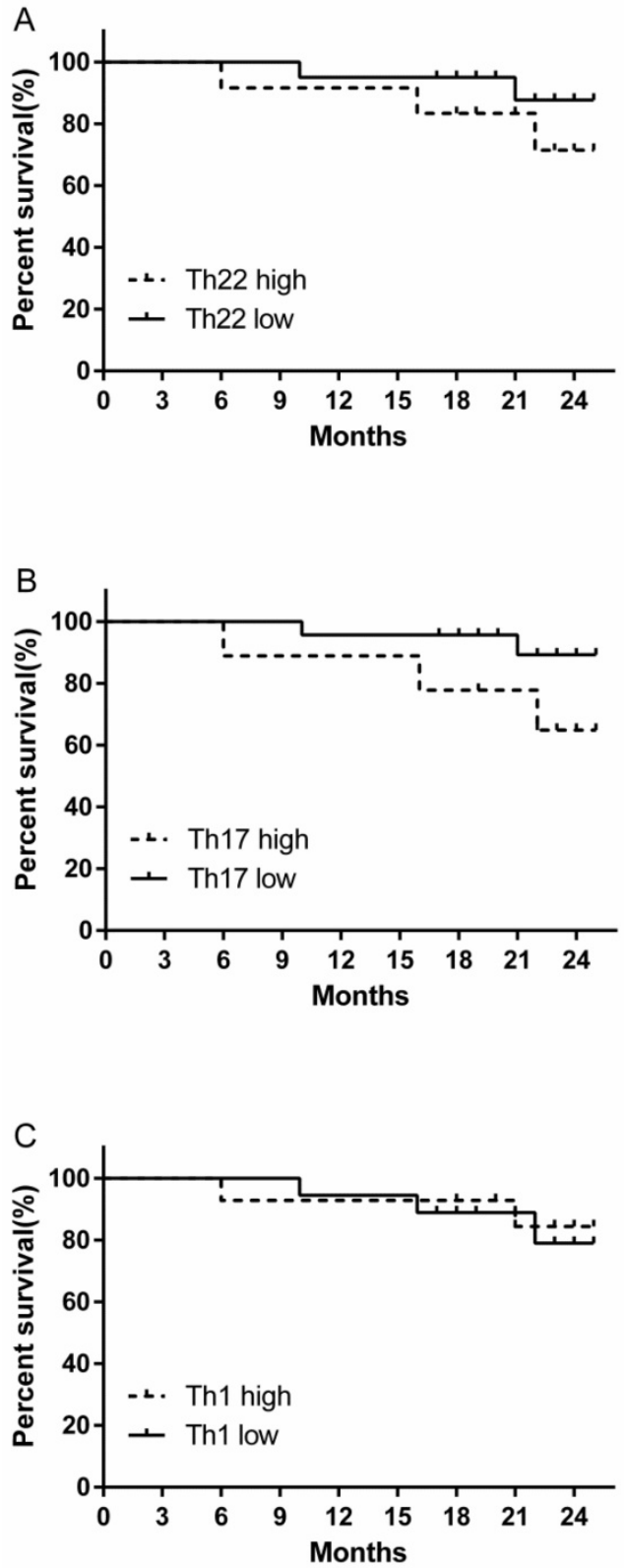

Figure 8. Kaplan-Meier curve for overall survival by median Th22, Th17 and Th1 cells in RCC patients. (A B) A decreased trend of survival rate was found in the patients with high Th22 or Th17 cell percentages compared with patients with low Th22 or Th17 cell level. (C) No similar trend of survival rate was found in patients between high versus low Thl cell percentage level.

\section{Discussion}

RCC was considered an immunologically sensitive cancer more than 30 years ago. Given that RCC tends to spread to distant sites, a reliable prognostic marker is required. It has been reported that some $\mathrm{CD}^{+} \mathrm{T}$ cells are essential for tumorigenesis and involved in different human cancers [25-27]. Our research evaluated the probable role of preoperative circulating Th22 cells and the related Th subsets levels in RCC.

As expected, our study showed a higher proportion of circulating Th22 and Th17 cells in RCC patients compared with healthy controls. These results indicate that Th22 and Th17 cells may be related to T-cell-mediated immunity in RCC patients. Th22 cells have recently been defined as CD4 ${ }^{+}$IFN- $\gamma^{-}$IL-17-IL-22 ${ }^{+}$cells. It is a newly identified independent Th subset compared to the well-known Th1 and Th17 subsets [16]. Th22 cells are thought to have an impact on certain tumors and autoimmune diseases. As we all know, little data is available on the role of Th22 cells in RCC. In our study, we found a significant increase in the frequency of Th22 cells in RCC patients compared to healthy controls, suggesting that Th22 cells may have a potential pathogenic role in RCC.

IL-22 is a member of the IL-10 cytokines family and is secreted mainly by activated Th22 cells [17]. The role of IL-22 in cancer progression has been recognized in some epithelial cancers, such as breast and lung cancer. When IL-22 is released by immune cells, it can act on cancer cells to promote tumor growth, aggressiveness, and treatment resistance [28-30]. Our study showed a significantly higher plasma IL-22 level in the RCC patients than the healthy controls. Furthermore, a significant correlation was found between the plasma IL-22 levels and Th22 cells in RCC patients, but no association in the healthy controls. A positive relationship between plasma IL-22 concentration and the frequency of Th22 cells in RCC may be explained by the fact that Th22 cells are a significant subset of IL-22 producing T cells, accounting for $37 \%$ to $63 \%$ of all IL-22-producing T cells [20].

Our current research also showed that Th22 cells increased with tumor stage and grade in RCC. Meanwhile, we observed a positive correlation between Th22 cells and tumor stage or grade. These data suggested that Th22 cells may be associated with tumor development and progression in RCC. We further studied AHR, the critical transcription factor directing Th22 lineage commitment, and found that the expression of AHR mRNA was increased in RCC patients. All of the above indicated that the Th22 subset was positively correlated with the occurrence and development of RCC and may promote tumor progression and affect the prognosis of RCC patients.

There has been controversy concerning the role of circulating Th17 cells in human tumor immunity [31]. Our research showed that the frequency of Th17 cells in RCC patients was not only increased but also associated with both tumor stage and grade. We also found a significant positive correlation between Th22 and Th17 cells in patients with RCC. These results indicated that in the occurrence and development of RCC, abnormal differentiation of Th22 and Th17 cells may be induced in the same way. 
RORC is the main transcription factor that plays a significant role in directing the Th17 lineage and modulates the polarization of Th22 cells [18]. We observed a significant increase in RORC expression in RCC patients. Th17 and Th22 polarization require the transcription factors RORC and AHR. Also, Th22 differentiation requires the transcription factor AHR [32-34]. Similarly, RORC and AHR are involved in IL-22 production [33, 34]. Consequently, these associations may prime Th22 and Th17 cells and prompt a positive correlation between Th22 and Th17 cells in RCC patients.

Studies have suggested that Th1 cells play an anti-tumor role by mediating cellular immunity, activating $\mathrm{CD}^{+}$CTL cells, and promoting reproduction by secreting IL-2 and IFN- $\gamma[35,36]$. Therefore, we tested the frequencies of circulating Th1 cells to investigate its possible role in RCC patients. However, no significant difference was found in Th1 cell levels between RCC patients and healthy controls. Generally, Th1-mediated cellular immunity was thought to be related to early tumors with a shift toward other Th immune responses in advanced tumors [37]. Onishi's study demonstrated that there was a change in the effective response from Th1 to Th2 with increasing stage of RCC [9]. Although our research showed that the frequencies of Th1 cells were lower in RCC patients than in healthy donors, the difference was not significant.

Furthermore, Th1 cells showed no sign of correlation with Th22 cells in RCC patients. Also, no significant association was found between Th1 cells and tumor stage or WHO/ISUP grade in RCC. The specific function of Th1 cells in the tumor pathogenesis of RCC needs further investigation.

We also assessed the clinical value of Th22, Th17, and Th1 cells in the overall survival of RCC patients. Our study found that patients with high Th22 or Th17 cells frequency displayed decreased survival rates. Although this difference was not statistically significant, it may be clinically relevant in the long run.

In summary, our study demonstrated that the frequencies of circulating Th22 and Th17 cells were elevated in RCC patients compared with healthy controls. Furthermore, circulating Th22 and Th17 cells showed a significant association with advanced RCC tumor stage and high WHO/ISUP grade.

Given that there are few prognostic factors for RCC, circulating Th22 and Th17 cells might be useful clinical markers for assessing tumor diagnosis and progression of RCC. Further investigations on the functions of Th22 and Th17 cells in RCC patients may be conducive to designing novel therapeutic interventions in the future.

\section{Acknowledgments}

This study was funded by the National Natural Science Foundation of China (grant number: 81600092), and the Key Research and Development Plan of Shandong Province (grant number: 2017GSF218003).

\section{Competing Interests}

The authors have declared that no competing interest exists.

\section{References}

1. Ferlay J, Soerjomataram I, Dikshit R, Eser S, Mathers C, Rebelo M, et al. Cancer incidence and mortality worldwide: sources, methods and major patterns in GLOBOCAN 2012. International journal of cancer. 2015; 136: E359-86.

2. Motzer RJ, Jonasch E, Agarwal N, Bhayani S, Bro WP, Chang SS, et al. Kidney Cancer, Version 2.2017, NCCN Clinical Practice Guidelines in Oncology. Journal of the National Comprehensive Cancer Network : JNCCN. 2017; 15: 804-34.

3. Figlin R, Sternberg C, Wood CG. Novel agents and approaches for advanced renal cell carcinoma. The Journal of urology. 2012; 188: 707-15.

4. McLaughlin JK, Lipworth L. Epidemiologic aspects of renal cell cancer. Seminars in oncology. 2000; 27: 115-23.

5. Gago-Dominguez M, Yuan JM, Castelao JE, Ross RK, Yu MC. Family history and risk of renal cell carcinoma. Cancer epidemiology, biomarkers \& prevention : a publication of the American Association for Cancer Research, cosponsored by the American Society of Preventive Oncology. 2001; 10: 1001-4.

6. Mattioli S, Truffelli D, Baldasseroni A, Risi A, Marchesini B, Giacomini C, et al. Occupational risk factors for renal cell cancer: a case--control study in northern Italy. Journal of occupational and environmental medicine. 2002; 44: 1028-36.

7. Islami F, Goding Sauer A, Miller KD, Siegel RL, Fedewa SA, Jacobs EJ, et al. Proportion and number of cancer cases and deaths attributable to potentially modifiable risk factors in the United States. CA: a cancer journal for clinicians. 2018; 68: 31-54.

8. Siegel RL, Miller KD, Jemal A. Cancer Statistics, 2017. CA: a cancer journal for clinicians. 2017; 67: 7-30.

9. Onishi T, Ohishi Y, Goto H, Tomita M, Abe K. An assessment of the immunological status of patients with renal cell carcinoma based on the relative abundance of T-helper 1- and -2 cytokine-producing CD4+ cells in peripheral blood. BJU international. 2001; 87: 755-9.

10. Kobayashi M, Kubo T, Komatsu K, Fujisaki A, Terauchi F, Natsui S, et al. Changes in peripheral blood immune cells: their prognostic significance in metastatic renal cell carcinoma patients treated with molecular targeted therapy. Med Oncol. 2013; 30: 556.

11. Cao X. Regulatory $\mathrm{T}$ cells and immune tolerance to tumors. Immunologic research. 2010; 46: 79-93

12. Zhang Y, Ma D, Tian Y, Wang X, Qiao Y, Cui B. The imbalance of Th17/Treg in patients with uterine cervical cancer. Clinica chimica acta; international journal of clinical chemistry. 2011; 412: 894-900.

13. Goedegebuure PS, Eberlein TJ. The role of CD4+ tumor-infiltrating lymphocytes in human solid tumors. Immunologic research. 1995; 14: 119-31.

14. Saxena R, Kaur J. Th1/Th2 cytokines and their genotypes as predictors of hepatitis B virus related hepatocellular carcinoma. World journal of hepatology. 2015; 7: 1572-80.

15. Ivanova EA, Orekhov AN. T Helper Lymphocyte Subsets and Plasticity in Autoimmunity and Cancer: An Overview. BioMed research international. 2015; 2015: 327470 .

16. Eyerich S, Eyerich K, Pennino D, Carbone T, Nasorri F, Pallotta S, et al. Th22 cells represent a distinct human $\mathrm{T}$ cell subset involved in epidermal immunity and remodeling. The Journal of clinical investigation. 2009; 119: 3573-85.

17. Trifari S, Kaplan CD, Tran EH, Crellin NK, Spits H. Identification of a human helper $\mathrm{T}$ cell population that has abundant production of interleukin 22 and is distinct from $\mathrm{T}(\mathrm{H})-17, \mathrm{~T}(\mathrm{H}) 1$ and $\mathrm{T}(\mathrm{H}) 2$ cells. Nature immunology. 2009; 10 : 864-71.

18. Duhen T, Geiger R, Jarrossay D, Lanzavecchia A, Sallusto F. Production of interleukin 22 but not interleukin 17 by a subset of human skin-homing memory T cells. Nature immunology. 2009; 10: 857-63.

19. Veldhoen M, Hirota K, Westendorf AM, Buer J, Dumoutier L, Renauld JC, et al. The aryl hydrocarbon receptor links TH17-cell-mediated autoimmunity to environmental toxins. Nature. 2008; 453: 106-9.

20. Wolk K, Witte E, Witte K, Warszawska K, Sabat R. Biology of interleukin-22. Seminars in immunopathology. 2010; 32: 17-31.

21. Di Lullo G, Marcatti M, Heltai S, Brunetto E, Tresoldi C, Bondanza A, et al. Th22 cells increase in poor prognosis multiple myeloma and promote tumor cell growth and survival. Oncoimmunology. 2015; 4: e1005460. 
22. Liu T, Peng L, Yu P, Zhao Y, Shi Y, Mao X, et al. Increased circulating Th22 and Th17 cells are associated with tumor progression and patient survival in human gastric cancer. Journal of clinical immunology. 2012; 32: 1332-9.

23. Qin S, Ma S, Huang X, Lu D, Zhou Y, Jiang H. Th22 cells are associated with hepatocellular carcinoma development and progression. Chinese journal of cancer research = Chung-kuo yen cheng yen chiu. 2014; 26: 135-41.

24. Huang YH, Cao YF, Jiang ZY, Zhang S, Gao F. Th22 cell accumulation is associated with colorectal cancer development. World journal of gastroenterology. 2015; 21: 4216-24.

25. Zhang W, Tian X, Mumtahana F, Jiao J, Zhang T, Croce KD, et al. The existence of Th22, pure Th17 and Th1 cells in CIN and Cervical Cancer along with their frequency variation in different stages of cervical cancer. BMC cancer. 2015; 15: 717.

26. Zhang W, Hou F, Zhang Y, Tian $Y$, Jiao J, Ma D, et al. Changes of Th17/Tc17 and Th17/Treg cells in endometrial carcinoma. Gynecologic oncology. 2014; 132: 599-605.

27. Gaur P, Qadir GA, Upadhyay S, Singh AK, Shukla NK, Das SN. Skewed immunological balance between Th17 (CD4(+)IL17A (+)) and Treg (CD4 $(+)$ CD25 (+)FOXP3 $(+))$ cells in human oral squamous cell carcinoma. Cell Oncol (Dordr). 2012; 35: 335-43

28. Lim C, Savan R. The role of the IL-22/IL-22R1 axis in cancer. Cytokine \& growth factor reviews. 2014; 25: 257-71.

29. Kim K, Kim G, Kim JY, Yun HJ, Lim SC, Choi HS. Interleukin-22 promotes epithelial cell transformation and breast tumorigenesis via MAP3K8 activation. Carcinogenesis. 2014; 35: 1352-61.

30. Shalapour S, Karin M. Immunity, inflammation, and cancer: an eternal fight between good and evil. The Journal of clinical investigation. 2015; 125: 3347-55.

31. Ye J, Livergood RS, Peng G. The role and regulation of human Th17 cells in tumor immunity. The American journal of pathology. 2013; 182: 10-20.

32. Ivanov, II, McKenzie BS, Zhou L, Tadokoro CE, Lepelley A, Lafaille JJ, et al. The orphan nuclear receptor RORgammat directs the differentiation program of proinflammatory IL-17+ T helper cells. Cell. 2006; 126: 1121-33.

33. Lee JS, Cella M, McDonald KG, Garlanda C, Kennedy GD, Nukaya M, et al. AHR drives the development of gut ILC22 cells and postnatal lymphoid tissues via pathways dependent on and independent of Notch. Nature immunology. 2011; 13: 144-51

34. Sawa S, Lochner M, Satoh-Takayama N, Dulauroy S, Berard M, Kleinschek M, et al. RORgammat+ innate lymphoid cells regulate intestinal homeostasis by integrating negative signals from the symbiotic microbiota. Nature immunology. 2011; 12: 320-6.

35. Nocera NF, Lee MC, De La Cruz LM, Rosemblit C, Czerniecki BJ. Restoring Lost Anti-HER-2 Th1 Immunity in Breast Cancer: A Crucial Role for Th1 Cytokines in Therapy and Prevention. Frontiers in pharmacology. 2016; 7: 356.

36. Hao CJ, Li J, Liu P, Li XL, Hu YQ, Sun JC, et al. Effects of the balance between type 1 and type $2 \mathrm{~T}$ helper cells on ovarian cancer. Genetics and molecular research : GMR. 2016; 15.

37. Wang SK, Zhu HF, He BS, Zhang ZY, Chen ZT, Wang ZZ, et al. CagA+ H pylori infection is associated with polarization of $\mathrm{T}$ helper cell immune responses in gastric carcinogenesis. World journal of gastroenterology. 2007; 13: 2923-31. 